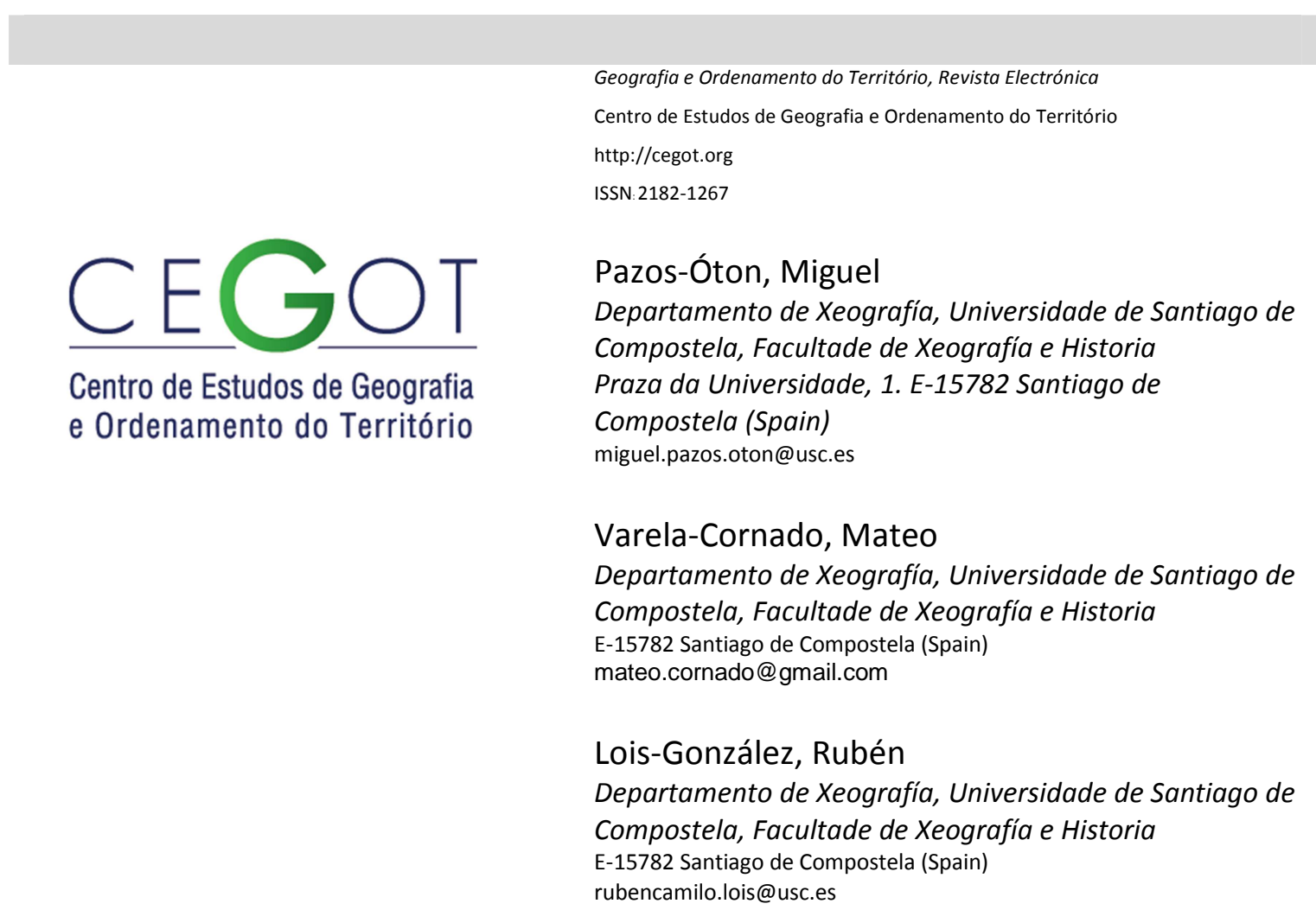

\title{
O corredor urbano atlántico de Galicia. Cara unha nova xeografía
} da mobilidade?

Referência: Pazos-Óton, Miguel et al. (2015). O corredor urbano atlántico de Galicia. Cara unha nova xeografía da mobilidade?. (GOT), n.o 7 (junho). Centro de Estudos de Geografia e Ordenamento do Território, p. 283300, dx.doi.org/10.17127/got/2015.7.013

\section{Resumen}

La reciente inauguración de la denominada línea de alta velocidad ferroviaria entre A Coruña y Vigo ha tenido una gran resonancia mediática y simbólica. En un espacio periférico dentro de España como es Galicia, con un tradicional déficit de infraestructuras de transporte, la vertebración ferroviaria del Corredor Atlántico es un hecho crucial para articular el territorio del Corredor Urbano Atlántico de Galicia, que se prolonga más allá del Miño hacia el norte de Portugal. El Corredor cuenta ahora con una óptima movilidad interciudades. Sin embargo, el sistema global de movilidad sufre problemas crónicos (congestión viaria, falta de transporte público local, ausencia de intermodalidad, etc) que no se solventan con la puesta en marcha del nuevo servicio. En el presente trabajo partimos de una caracterización del Corredor Urbano Atlántico, para analizar después la dotación de infraestructuras. Finalmente, examinamos las consecuencias del nuevo servicio ferroviario desde un punto de vista territorial.

Palabras-Clave: Corredor Urbano Atlántico, Galicia, movilidad, ferrocarril 


\title{
Resumo
}

O corredor urbano atlântico da Galiza. Rumo a uma nova geografia da mobilidade?

A recente abertura da chamada linha ferroviária de alta velocidade entre a Corunha e Vigo teve muita ressonância simbólica e mediática. Numa área periférica dentro da Espanha como a Galiza, com deficit tradicional em infraestruturas de transporte, a espinha dorsal ferroviária do Corredor Atlântico é um fato crucial para articular o território do Corredor Urbano Atlântico Galiza, que se estende para além do Minho ao norte de Portugal. 0 Corredor tem agora uma ótima mobilidade interurbana. No entanto, o sistema de mobilidade global sofre problemas crônicos (congestionamento rodoviário, a falta de transporte público local, ausência intermodal, etc) que no se solucionarão com o lançamento do novo serviço. Neste artigo, partimos de uma caracterização do Corredor Urbano Atlântico, antes de forcar na infraestrutura existente. Finalmente, examinamos as consequências do novo serviço ferroviário de um ponto de vista territorial.

Palavras-Chave: Corredor Urbano Atlântico, Galiza, mobilidade, transporte ferroviário

\begin{abstract}
The Urban Atlantic Corridor of Galicia. Towards a new geography of mobility?

The recent opening of the so-called high-speed rail line between A Coruna and Vigo had a lot of media and symbolic resonance. In an peripheral area within Spain such as Galicia, with a traditional deficit in transport infrastructure, the railway line of the Atlantic Corridor is crucial to articulate the territory of the Urban Corridor Atlantic Galicia, which extends beyond the Minho to the north of Portugal. The Corridor now has an excellent intercity mobility. However, global mobility system suffers chronic problems (road congestion, lack of local public transport, intermodal absence, etc) not be solved with the launch of the new service. In this paper we start from a characterization of the Urban Atlantic Corridor, before analyzing the existing infrastructure. Finally, we examine the consequences of the new rail service from a territorial point of view.
\end{abstract}

Keywords: Urban Corridor Atlantic, Galicia, mobility, rail

Unha primeira reflexión xeográfica que se debe facer sobre o impacto que as novas infraestruturas ferroviarias traerán a Galicia, contempla dúas perspectivas, con outras tantas variables cada unha. Por unha banda, a organización do espazo do país mostra unha forte urbanización e polarización do crecemento na súa faixa litoral (Lois, 2004; Lois e Piñeira, 2011). A mellora na conexión por tren entre as cidades do corredor atlántico e a redución substancial da distancia medida en tempo favorecerá sen dúbida a complementariedade do sistema urbano e cambiará a Xeografía desta franxa clave na organización do país (Pazos, 2005). Por outra, a opción polos ferrocarrís rápidos introducirá un primeiro cambio fundamental nos modos de transporte empregados polos cidadáns. A 
absoluta hexemonía do automóbil particular declinará e ábrese un novo tempo para o uso cotián do transporte rápido, onde agardemos que os sistemas públicos de mobilidade (ferrocarril + autobús + cercanías...) rematen por imporse. Así e todo, xunto a estas novidades indubidablemente positivas que conlevará a apertura de novas liñas de tren no corredor atlántico, non podemos esquecer cando menos dous impactos negativos, que sería bo corrixir canto antes. O primeiro, o reforzamento do papel das cidades principais na definición do sistema urbano galego: estes trens saen e chegan ás estacións da cidade compacta, reforzan a súa centralidade, pero isto pódese acompañar dunha perda de frecuencias (e conectividade) para estacións periurbanas, ou das vilas e pequenas cidades (Pazos, 2009). Ademais, gáñase en tempo de desprazamento, pero poden incrementarse os problemas de acceso ás estacións (aparcamento, conxestións das liñas de autobús urbano, do tráfico en xeral, etc.). Para isto último, cumpre afirmar que unha mellora e pequena reorganización do transporte metropolitano e de cercanías, solucionaría sen dúbida a maior parte das dificultades de conxestión enunciadas nos arredores das terminais ferroviarias.

No presente artigo, e tendo en conta o noso obxectivo de relacionar Xeografía da mobilidade con novos eixos de transporte rápido en Galicia, partirase dun primeiro apartado onde trataremos de definir qué é o corredor (ou o eixo urbano) atlántico e como se estrutura internamente. O segundo epígrafe reservarase a describir as infraestruturas de comunicación fundamentais no corredor até o presente. Na terceira parte, centrarémonos na análise da accesibilidade ferroviaria actual e prevista a partir de agora, para rematar cunha conclusión sobre a importancia do tren de alta velocidade na transformación territorial do occidente de Galicia.

\section{Unha caracterización xeográfica do Corredor (Eixo) Urbano atlántico galego}

A maior parte da literatura xeográfica dos últimos decenios coincide en afirmar a existencia dun eixo de desenvolvemento territorial e urbano (un corredor en disposición meridiana), que desde Ferrolterra até a área metropolitana de Vigo e a fronteira con Portugal articula cinco das principais cidades galegas (Ferrol, A Coruña, Santiago de Compostela, Pontevedra e Vigo), e concentra máis das dúas partes da poboación do país en aproximadamente un 
quinto da súa superficie (Piñeira e Santos, 2011; DOT, 2011; Lois, 2014). Ao longo dos anos 1970 e 1980, diversos autores observaron procesos de difusión urbana ao redor de $A$ Coruña e Ferrol no Norte, e Vigo e Pontevedra no Sur, entre os que se situaban unha cidade con importancia crecente como era Santiago ao converterse en capital da Comunidade Autónoma e a densa área de ocupación humana de Pontevedra e as penínsulas do Morrazo, o Salnés e o Sur do Barbanza (Precedo, 1987; Souto, 1988). Aínda que nese período a caracterización desta realidade insistía máis en definir as rexións urbanas de VigoPontevedra ou A Coruña-Ferrol como dúas realidades que se desenvolvían en paralelo, cunha crecente urbanización intermedia, coa finalización da Autoestrada do Atlántico e a consolidación da autonomía de Galicia, estas interpretacións foron deixando paso ás que insisten en considerar a existencia dun eixo de desenvolvemento territorial ou corredor atlántico de disposición Norte-Sur na fachada litoral occidental do país.

Este corredor debe analizarse como unha estrutura policéntrica, onde a potencialidade económica e demográfica da área metropolitana de Vigo (en torno a 500.000 habitantes) e A Coruña (uns 450.000), non resta protagonismo e autonomía funcional á área de Santiago (que acada os 160.000 habitantes), a Ferrolterra (que a pesar do seu declive mantense sobre 150.000 residentes) e á área de Pontevedra (que, sen dúbida, supera os 100.000 aínda que a súa delimitación exclúa boa parte do Salnés). Ademais, determinados espazos periurbanos e/ou encabezados por unha pequena cidade ou unha vila crearon realidades coherentes internamente, cunha poboación que gravita, pero non depende para moitas tarefas das súas cidades principais máis próximas. Estas áreas esténdese desde o Norte (Bergantiños, As Mariñas betanceiras, O Eume) até o Sur (Val Miñor, Baixo Miño, O Condado), pasando polas tres penínsulas formadas entre as Rías Baixas, que xa citamos anteriormente (VV.AA., 2014). Nestes sectores, concéntranse varios centos de miles de galegos máis e agromaron núcleos urbanos importantes como Vilagarcía de Arousa, Carballo, Ribeira, Tui, Cangas ou Betanzos, entre outros, que xa mostran algúns trazos de mobilidade interna propios de cidades compactas de certa entidade (ver figura 1). 


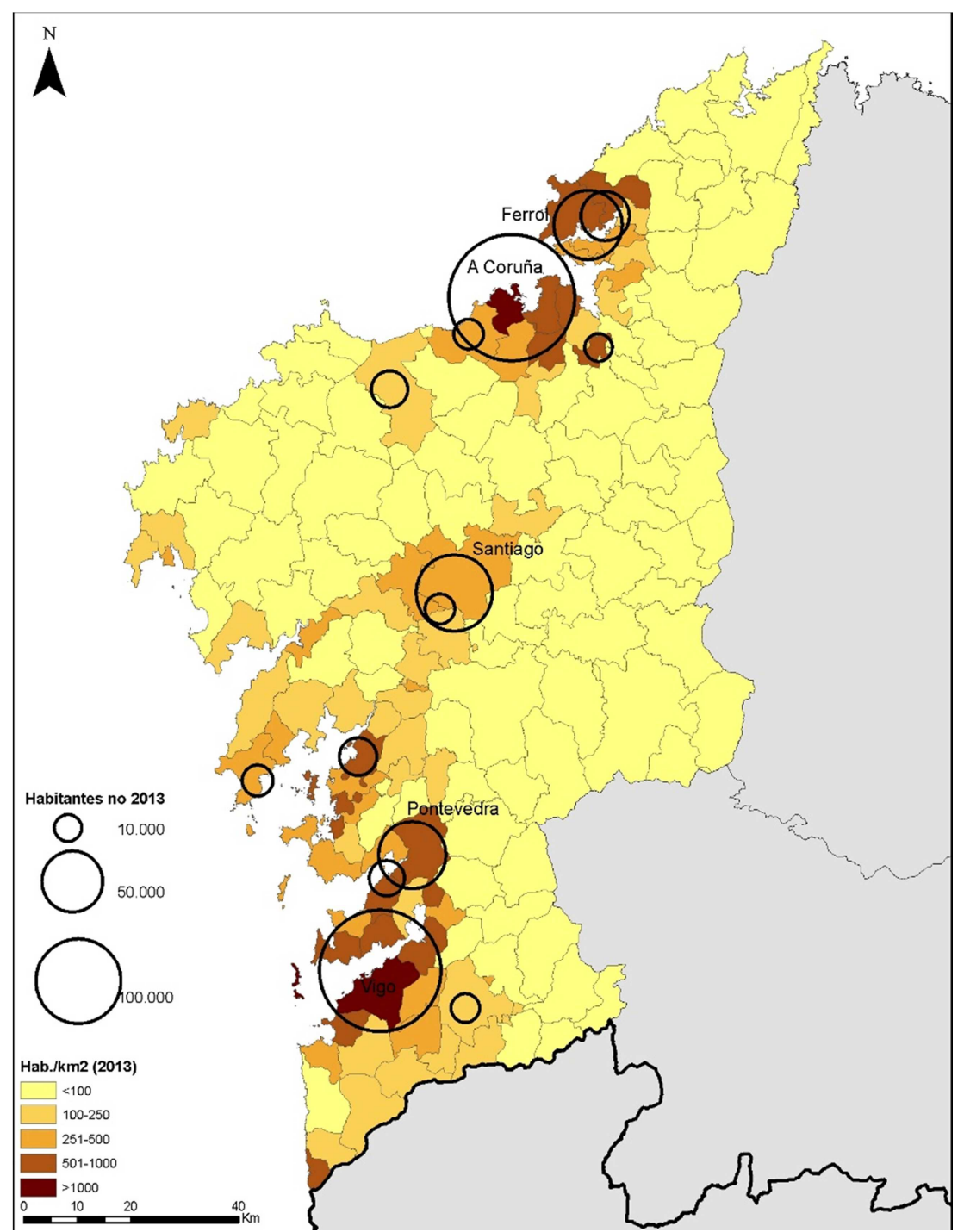

Figura 1: Poboación e densidade de poboación nos municipios da Galicia Occidental Autor: Mateo Varela Cornado a partir de datos do IGE-INE

Como se acaba de sinalar, o corredor atlántico defínese por unha ocupación e urbanización continúa do territorio. No mesmo aparecen tanto cidades clásicas como núcleos satélites das mesmas, urbanizacións da periferia, cabeceiras comarcais e antigos espazos rurais densificados tanto pola construción das denominadas urbanizacións como por novas vivendas unifamiliares diseminadas polo espazo. Esta realidade xeográfica e poboacional tan complexa xera innumerables problemas de xestión da mobilidade ou na prestación de servizos, entre outros moitos. Se á proliferación de distintos tipos de entidades habitadas lle engadimos a existencia dunha actividade económica intensa, nunha estrutura diversificada, non sorprenderá que a Ordenación do Territorio requirida para a Galicia occidental sexa moi complexa e apareza sometida a un continuo debate, xa que as medidas ate agora adoptadas 
non deron conta da magnitude de desafíos de gobernanza territorial plantexados (Lois e Aldrey, 2010; Rodríguez González, 2010).

Entre os sectores económicos ben representados neste espazo está unha agricultura intensiva, que se complementa coa explotación pesqueira e marisqueira moi significativa das augas interiores das rías e das augas próximas, e cun sector agroalimentario relevante, fragmentado en centos de empresas. Una tradición industrial non desbotable, que se traduce na existencia de importantes espazos e parques empresariais en Vigo-O Porriño, A Coruña-Arteixo-Betanzos e na comarca de Ferrol, en menor medida nas áreas de Santiago e Pontevedra, e ao redor doutras pequenas cidades e núcleos cabeceira. Como se pode deducir, esta proliferación de actividades produtivas no territorio complica, aínda máis, a xestión da mobilidade e os problemas de tráfico e de acceso a determinados nodos vitais na xeración de riqueza para o conxunto do país (portos, polígonos industrias ou grandes fábricas de localización urbana, almacéns, etc.). A conectividade intermodal, a construción de novos enlaces viarios e a regulamentación do tráfico, constitúen tarefas cotiás no goberno destes centros económicos, polo xeral moi distribuídos polos espazos urbanos e con necesidades específicas de transporte para as súas materias primas e produtos elaborados.

Onde si existe unha lóxica un pouco máis clara de localización, unha certa xerarquía dotacional, é no sector servizos. Tanto o comercio minorista como os servizos públicos e administrativos e as actividades financeiras ou de seguros, seguen unha organización territorial que prioriza as cidades e as áreas máis poboadas, e vai perdendo densidade conforme descendemos chanzos na xerarquía urbana ou diminúe a intensidade da urbanización. En calquera caso, esta maior simplicidade no tratamento destas actividades non pode facernos esquecer que a xestión dos desprazamentos pautados dos alumnos cando se dirixen a un centro educativo, dos enfermos cando van a un centro de atención primaria ou a un hospital, ou dos cidadáns cando mercan diferentes produtos, debuxa un perfil de mobilidade continua, en moitas ocasións concentrada e que necesita dunha organización flexible, pero racional, que procure conxugar demandas de mobilidade rápida ás veces confrontadas entre si

Finalmente, cabe precisar que o corredor atlántico galego forma parte dunha realidade máis ampla, onde unha poboación maior e un conxunto de actividades económicas moi diverso 
necesitan aproveitar de xeito eficiente o espazo, relacionarse e desprazarse. Como a maioría dos autores coincide en sinalar, o eixo urbano galego intégrase noutro maior galegoportugués que se alonga cara o Sur en dirección á área metropolitana do Porto, Coimbra e Aveiro, e á rexión lisboeta. Este corredor, e así o observou o sociólogo canadiano R. Florida a partir de imaxes nocturnas por satélite, supón a máis importante concentración urbana e humana da Península Ibérica, de entidade superior incluso que o corredor mediterráneo ou que Madrid e as súas amplas periferias (Florida, Gulden e Mellander, 2008; López Carro, 2014). Por iso, calquera intervención en accesibilidade que se realice neste amplo sector, posúe unha influencia significativa na estrutura territorial de España e Portugal, e por suposto no papel que pode desenvolver no contexto da Europa unida.

\section{As infraestruturas existentes no Corredor Atlántico}

Na actualidade, o Corredor Atlántico está a desempeñar o papel de main street ou "grande rúa" (Nárdiz, 2008) de Galicia. O sistema policéntrico ao que xa nos temos referido hai un momento está cada vez máis integrado, algo que non se pode comprender sen ter en conta as grandes mudanzas que se produciron nos incrementos da mobilidade da poboación en dito corredor.

O papel das infraestruturas de transportes neste aumento da mobilidade é fundamental. Desde a década dos oitenta, o poder autonómico galego amosou unha especial preocupación pola modernización do sistema viario interno. Sempre se considerou que unha boa parte da culpa do tradicional "atraso" de Galicia foi o déficit de infraestruturas (Beiras, 1973; VV.AA., 1984).

En canto ás infraestruturas de interese xeral do Estado, dende a chegada da democracia houbo consenso entre todos os axentes políticos e sociais en demandar melloras claras ao goberno central. Neste senso, a primeira infraestrutura de grande capacidade coa que contou Galicia foi a Autoestrada do Atlántico, auténtica espiña dorsal do Corredor Atlántico. Foi unha infraestrutura deseñada e executada por iniciativa estatal, coa fin de crear sinerxias entre os dous Polos de Desenvolvemento, A Coruña e Vigo. O seu papel foi e é estratéxico tamén na relación de Galicia co Norte de Portugal. 
Desde o primeiro momento, a Autoestrada do Atlántico naceu coa vontade de achegar entre si os dous focos demográficos e económicos máis importantes do País, con Santiago de Compostela como punto de equilibrio (Pérez Touriño, 1997). Os primeiros tramos abertos á circulación foron entre A Coruña e Santiago de Compostela, por unha banda, e entre Pontevedra e Vigo, por outra (coa inauguración da emblemática Ponte de Rande). Nos anos sucesivos, e ao longo da década dos 1990-2000 e 2000-2010, foron avanzando as obras ata completar a totalidade da conexión viaria de alta capacidade entre Ferrol e Tui, enlazando coa A3 portuguesa.

En paralelo, a Xunta de Galicia foi executando vías rápidas e autovías que partían da Autoestrada do Atlántico cara espazos dinámicos, como o Barbanza, o Salnés, o Morrazo ou a Ría de Muros e Noia, apostando exclusivamente por infraestruturas viarias (modelo baseado no "asfalto"). A Autoestrada do Atántico (na actuualidade, AP-9) pasou a ser imprescindible nas comunicacións na metade occidental de Galicia, co agravante de que dende o primeiro momento foi unha vía de peaxe.

Temos, polo tanto, unha vía estruturante, á cal non existe alternativa real (a N-550 está moi conxestionada e conta con moitas travesías urbanas), o que condiciona a mobilidade de aproximadamente dous millóns de persoas (ver figura 2). 


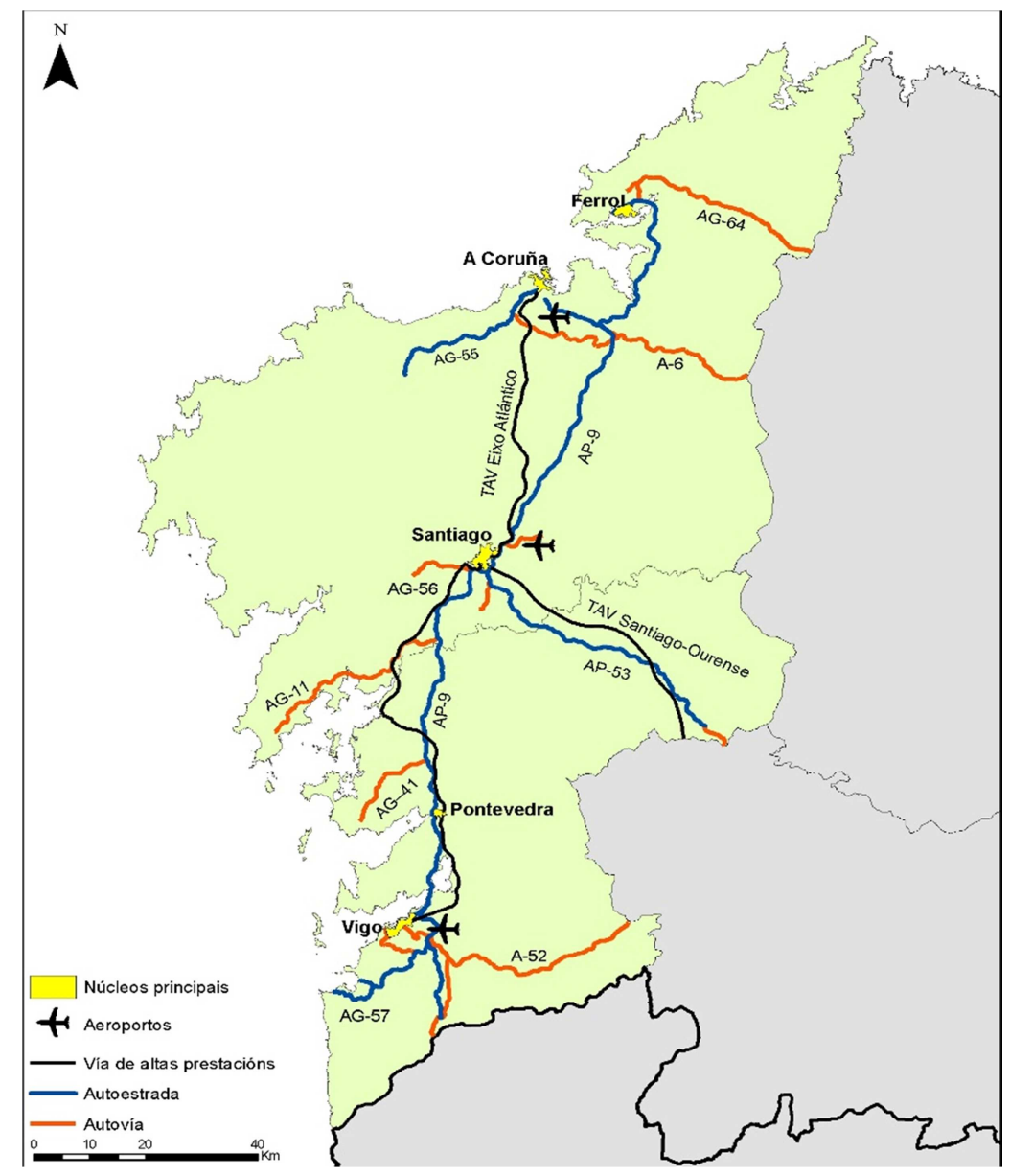

Figura 2: Principais infraestruturas de transporte no Corredor Atlańtico galego Autor: Mateo Varela Cornado

En todo este tempo, a AP-9 está sendo a única posibilidade real para os desprazamentos na práctica totalidade da Galicia Occidental. Non só polo que vimos de mencionar, senon polas eivas do transporte ferroviario ata o momento. É de xustiza sinalar a importancia das melloras na accesibilidade que se teñen producido entre A Coruña e Santiago de Compostela (o percorrido é de pouco máis de media hora na actualidade), e por suposto a conclusión do eixo ferroviario atlántico ata Vigo será moi positiva. Porén, detectamos varios problemas na actualidade:

1.- O mapa das vías férreas non sufriu modificacións dende hai moitas décadas. O servizo ferroviario só abrangue aos espazos nodais da Galicia Atlántica. Fican sen servizo ferroviario importantes comarcas como Bergantiños, Barbanza, Salnés, Morrazo, Baixo Miño, etc. 
2.- Non existen servizos de cercanías ou proximidade nas áreas urbanas e metropolitanas galegas. Por moito que o servizo ferroviario sexa óptimo entre os nodos urbanos agás Ferrol (A Coruña, Santiago, Vilagarcía, Pontevedra e Vigo), quedan sen vertebrar os espazos periurbanos que se expandiron nas últimas décadas a partir das cidades centrais (primeiras e segundas coroas urbanas).

3.- Hai unha tendencia clara á diminución de frecuencias ou supresión do servizo en estacións secundarias, como Cerceda, Padrón, Pontecesures, Portas, etc. A potenciación dos servizos "intercidades" vai en detrimento da cohesión territorial na Galicia Atlántica, xa que os nodos urbanos incrementan a súa centralidade a costa do resto do territorio. Neste contexto, son varias as estacións que se teñen pechado ou que están próximas a pecharse (ver figura 3).

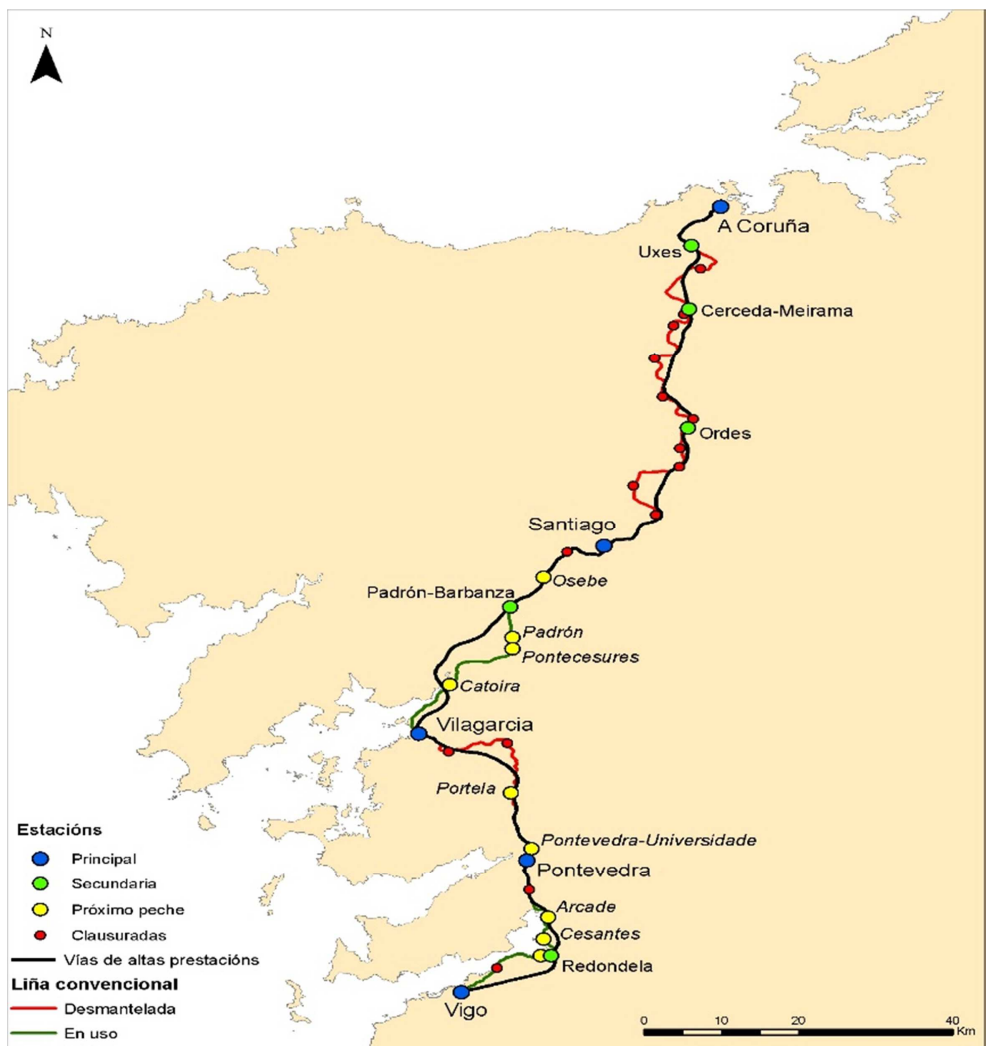

Figura 3: As estacións de ferrocarril no Corredor Atlántico galego Autor: Mateo Varela Cornado

Polo contrario, moitos destes espazos intersticiais pasan a depender exclusivamente da mobilidade viaria, cos condicionantes que esta implica: maior prezo, peaxes na AP-9, disponibilidade de automóbil particular, escasa oferta e intermodalidade dos horarios de autobuses, etc. 
Apesares de que o primeiro tramo do Eixo Atlántico foxe inaugurado en 2003, tiveron que pasaron 12 anos para que Vigo e A Coruña estean conectadas completamente mediante unha liña de altas prestacións. Foi no 2009, é dicir, 6 anos de obras e reformas nas liñas ferroviarias, para que as cidades de A Coruña e Santiago de Compostela estean a pouco máis de media hora en tren. Isto supuxo non só unha redución dos tempos das viaxes, tamén un aumento do número de viaxeiros. Con respecto ós tramo do sur de Galiza, a súa finalización foi moito máis tardía, concretamente 6 anos. Non será até o 2015 cando se dean por finalizadas as propias obras e a súa posterior inauguración. Tamén temos que ter en conta a maior complexidade dos tramos, destacando a construción do viaduto sobre a desembocadura do rio Ulla en Catoira (Pontevedra). Non só se tratou de construción de novos tramos e consigo un número elevado de pontes e túneles debido á orografía galega, tamén de novos accesos ás cidades e estacións. A maior transformación verase en Vigo, non só polo túnel de acceso de máis de $8 \mathrm{~km}$ de lonxitude, se non que tamén pola reformada estación, Vigo-Urzaiz. Unha infraestrutura que comenzará a dar servizo tan só ás liñas ferroviarias do Eixo Atlántico mentres que a súa función inicial como estación intermodal terá que esperar até 2018. (Ver Figura 4)

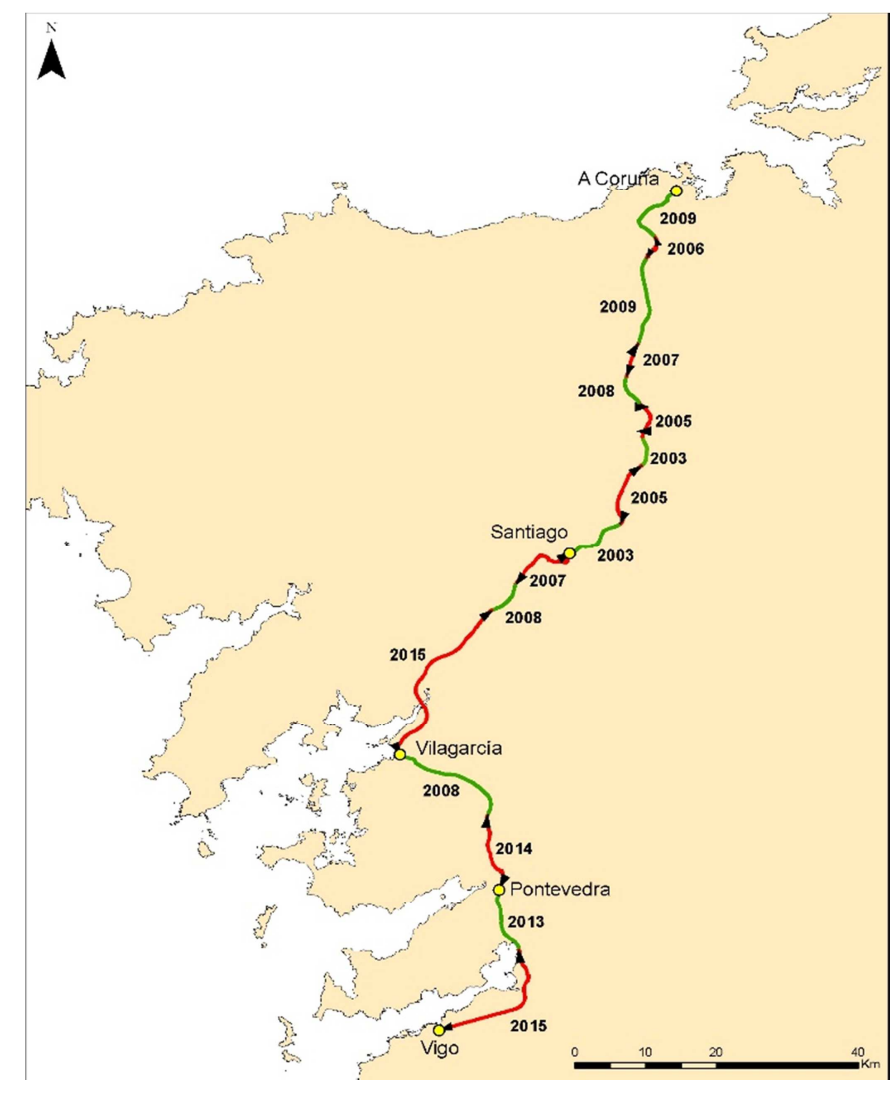

Figura 4: Ano de apertura dos novos tramos ferroviários. Autor: Mateo Varela Cornado 


\section{A accesibilidade e as novas mobilidades no Corredor Atlántico}

A posta en funcionamento do novo ferrocarril vai supoñer un cambio notable nunha parte do Eixo Atlántico galego no que se refire á accesibilidade e mobilidade. O espazo comprendido entre A Coruña, Santiago de Compostela, Vilagarcía de Arousa, Pontevedra e Vigo vaise comprimir, o que fará posible novos xeitos de vivir o territorio e suporá posibilidades antes inéditas. Cos novos tempos de percorrido, a relación Vilagarcía de Arousa-Santiago de Compostela equivalerá en tempo a un desprazamento de cercanías dentro dunha grande área metropolitana do tipo de Madrid ou Barcelona. O mesmo cabe dicir doutras relacións como Vigo-Pontevedra.

A nova infraestrutura e consigo os novos servizos ferroviarios supoñen unha mellora considerable nos tempos das viaxes. Coa apertura plena do tramo entre Compostela e A Coruña no 2009, os tempos reducíronse dos 90 minutos da liña convencional até os 40 minutos actuais. Hai que ter en conta que dende o 2011, coa entrada dos servizos eléctricos Avant, certas frecuencias viron reducido os seus tempos até só 28 minutos. Ben é certo que o aumento da velocidade media dos servizos supón tamén un número menor de paradas (Troin, 1995). Isto supuxo a redución do número de estacións con servizo, sendo clausuradas 11 en total mentres que tan só hai 3 estacións intermedias con servizos, OrdesFosado, Cerceda-Meirama e Uxes. A clausura de certas estacións, non veu dada só polos novos servizos, se non que tamén por como se construíu a nova vía ferroviaria. Para a construción de liñas de alta velocidade hai 2 opcións,por unha parte unha liña totalmente nova como a construída entre Compostela e Ourense. Unha segunda opción é adecuación da liña convencional para obter unha velocidade media máis alta. A opción elixida no Eixo Atlántico en Galicia foi un mixto entre estas dúas, onde houbo tramos renovados e outros totalmente novos. Isto provocou que certos tramos da antiga liña convencional foxen desmantelados ó ser inservibles. (Fernández Díaz, 2006)

Con respecto ós tramos do sur de Galicia, a posta en marcha das novas liñas ferroviarias suporá ó igual que no anterior, un salto de calidade. Na actualidade, o servizo máis rápido entre Vigo e a capital galega é de unha hora e vinte minutos. Sendo este o servizo que só para nas principais estacións (Pontevedra e Vilagarcía). Coa inauguración, os tempos 
reduciranse até os 45 minutos aproximadamente mentres que a conexión entre as dúas principais cidades galegas, Vigo e A Coruña, está prevista en pouco máis dunha hora de traxecto. Sendo máis competitivo que o vehículo privado. Ó igual que nos tramos do norte, a construción das novas liñas foi mixta mais neste haberá un pequeno tramo da liña convencional que seguirá en funcionamento, o que dá uso ás localidades de Padrón e Pontecesures. Por este tramo, unha vez aberto ó servizo comercial na nova liña, seguirán circulando trens mais coa incerteza dun posible peche no futuro. Sobre todo tendo en conta a apertura da nova estación de Padrón-Barbanza na liña de alta velocidade.

Porén, como ten sinalado Colomer (2010), a fortaleza dunha cadea modal e intermodal de transportes é equivalente á fortaleza do eslabón máis feble. A pesar de ter un eslabón de aceiro no tronco principal do Eixo, a cadea é feble no transporte local e metropolitano, que se debería articular en torno aos principais nodos urbanos. Isto é un inconveniente, xa que o transporte local e metropolitano (comarcal) tería que desempeñar un papel de feeder ou alimentador de viaxeiros ao ferrocarril atlántico.

Non existen outros servizos de camiños de ferro que conecten co corredor ferroviario atlántico (cercanías ou rexionais). Ademais o transporte en autobús presenta certos problemas de operatividade. O proxecto do Transporte Metropolitano da Xunta colleitou éxitos, pero no seu conxunto non termina de funcionar, por non ser un servizo integral e integrado plenamente entre as concesións autonómicas, os operadores locais e o operador ferroviario actual, RENFE. Ademais, non debemos esquecer que a cidade máis populosa de Galicia, Vigo, fica á marxe do Transporte Metropolitano.

Alén de que Betanzos, Miño, Pontedeume e Ferrol fiquen (ao igual que o Baixo Miño e a relación estratéxica con Portugal) fóra deste novo servizo ferroviario, existe unha definición conceptual pouco clara sobre o tipo de ferrocarril do que estamos a tratar.

A grande densidade de poboación e o desenvolvemento dunha rede urbana forte en só 130 kilómetros faría necesario outro tipo de ferrocarril, de características intermedias entre as cercanías e a longa distancia. É difícil pensar que o Corredor Atlántico pode estar estruturado por un tren de alta velocidade, cando sabemos que debe existir unha distancia mínima de máis de 100 kilómetros entre os sucesivos nodos urbanos conectados polo TAV. 
É patente unha certa confusión conceptual é patente cando se escoitan conceptos como o de "cercanías de alta velocidade", algo que en si mesmo é unha contradicción. Cómpre definir ben o servizo ferroviario que convén a Galicia, tendo en conta as particularidades da súa rede urbana e do seu sistema de asentamentos, e non transpoñer modelos que poden funcionar para outros territorios, pero non teñen por que ser válidos para o caso galego.

En todo o proceso de planificación da nova infraestrutura, resulta difícil comprender que ningún dos tres aeroportos galegos sexa accesible a través do novo servizo ferroviario. Tamén é criticable o desmantelamento do antigo trazado ferroviario e a retirada das travesas e os carrís, cando esta infraestrutura podería ser reutilizada para poñer en marcha uns servizos de proximidade.

A pesar da sensibilización dos poderes públicos e da cidadanía en xeral co problema da conxestión viaria, nas últimas décadas non se formulou oficialmente ningún proxecto para construir novas liñas férreas, que serían moi pertinentes en espazos como 0 Morrazo, 0 Barbanza, O Salnés ou Bergantiños, por poñer algúns exemplos. Mentres en Comunidades Autónomas como Cataluña, Euskadi, Andalucía ou Baleares creáronse compañías de camiños de ferro propias, en Galicia houbo unha práctica inactividade neste senso.

Un último aspecto a tratar refírese ás estacións desta nova liña. No treito A Coruña-Santiago de Compostela, a estación Ordes-Fosado, de nova planta, atópase nun estado de práctico abandono. A distancia con respecto á vila de Ordes e a ausencia de persoal na propia estación configuran unha auténtica gare-en-campagne (Troin, 1995) sen viaxeiros, e na que xa non paran case trens. Os servizos intercidades trunfan en detrimento dos rexionais. Este tipo de gare-verts ou estacións en campo aberto satisfacen ambicións políticas pero son escasamente operativas na mobilidade cotiá da poboación. Un caso semellante pode terminar sendo a futura estación Padrón-Barbanza, que corre o risco de converterse nunha estación sen viaxeiros.

En resumo, o novo servizo ferroviario vai conlevar a unha maior centralidade dos principais núcleos de poboación, A Coruña, Santiago de Compostela, Vilagarcía de Arousa, Pontevedra e Vigo. Na actualidade xa existen diferenzas en canto á accesibilidade e ó número de frecuencias. Estes 5 núcleos son os únicos que teñen máis de 15 servizos diarios, moitos destes directos entre as cidades, destacando os casos da Coruña e Santiago de Compostela, 
debido non só ós servizos directos de Media Distancia, senon tamén por mor do servizo do Avant, que se prolonga ata Ourense (ver táboa 1).

\begin{tabular}{|l|l|l|l|l|l|l|l|l|l|l|l|l|l|l|l|l|l|}
\hline & COR & UXE & CER & ORD & SDC & OSE & PAD & POC & CAT & VIL & PO-U & PON & ARC & CES & RE-P & RED & VGO \\
\hline COR & X & 4 & 7 & 4 & 21 & 1 & 9 & 9 & 6 & 16 & 1 & 16 & 7 & 1 & 6 & 6 & 16 \\
\hline UXE & 5 & X & 4 & 4 & 4 & 1 & 4 & 4 & 4 & 4 & 1 & 4 & 4 & 1 & 4 & 4 & 4 \\
\hline CER & 8 & 5 & X & 4 & 7 & 1 & 6 & 6 & 6 & 6 & 1 & 6 & 6 & 1 & 6 & 6 & 6 \\
\hline ORD & 4 & 4 & 4 & X & 4 & 1 & 4 & 4 & 4 & 4 & 1 & 4 & 4 & 1 & 4 & 4 & 4 \\
\hline SDC & 21 & 5 & 8 & 4 & $X$ & 1 & 10 & 10 & 7 & 17 & 1 & 17 & 8 & 1 & 7 & 7 & 17 \\
\hline OSE & 1 & 1 & 1 & 1 & 1 & X & 1 & 1 & 1 & 1 & 1 & 1 & 1 & 1 & 1 & 1 & 1 \\
\hline PAD & 8 & 4 & 7 & 3 & 10 & 1 & X & 10 & 7 & 10 & 1 & 10 & 10 & 1 & 7 & 7 & 10 \\
\hline POC & 8 & 4 & 7 & 3 & 9 & 1 & 9 & $X$ & 7 & 10 & 1 & 10 & 8 & 1 & 7 & 7 & 10 \\
\hline CAT & 6 & 4 & 6 & 3 & 7 & 1 & 7 & 7 & $X$ & 7 & 1 & 7 & 7 & 1 & 7 & 7 & 7 \\
\hline VIL & 16 & 4 & 7 & 3 & 17 & 1 & 9 & 9 & 7 & $X$ & 1 & 17 & 8 & 1 & 7 & 7 & 17 \\
\hline PO-U & 1 & 1 & 1 & 1 & 1 & 1 & 1 & 1 & 1 & 1 & X & 1 & 1 & 1 & 1 & 1 & 1 \\
\hline PON & 16 & 4 & 7 & 3 & 17 & 1 & 9 & 9 & 7 & 17 & 1 & X & 10 & 1 & 10 & 10 & 20 \\
\hline ARC & 6 & 3 & 6 & 2 & 7 & 1 & 7 & 7 & 6 & 7 & 1 & 10 & X & 1 & 9 & 9 & 10 \\
\hline CES & 1 & 1 & 1 & 1 & 1 & 1 & 1 & 1 & 1 & 1 & 1 & 1 & 1 & $X$ & 1 & 1 & 1 \\
\hline RE-P & 6 & 4 & 6 & 3 & 7 & 1 & 7 & 7 & 7 & 7 & 1 & 10 & 9 & 1 & $X$ & 10 & 10 \\
\hline RED & 9 & 4 & 7 & 3 & 10 & 1 & 8 & 8 & 7 & 10 & 1 & 13 & 10 & 1 & 10 & X & 15 \\
\hline VGO & 16 & 4 & 7 & 3 & 17 & 1 & 9 & 9 & 7 & 17 & 1 & 19 & 10 & 1 & 10 & 19 & X \\
\hline
\end{tabular}

COR: A Coruña; UXE: Uxes; CER: Cerceda; ORD: Ordes-Fosado; SDC: Santiago de Compostela; OSE: Osebe; PAD: Padrón: POC: Pontecesures; CAT: Catoira: VIL: Vilagarcía; PO-U: Pontevedra-Universidade; PON: Pontevedra; ARC: Arcade; CES: Cesantes: RE-P: Redondela-Picota; RED: Redondela; VIG: Vigo.

Táboa 1: Número de frecuencias en día laborable no Corredor Atlántico galego Autor: Mateo Varela Cornado a partir de datos de RENFE

O feito de seren os principais núcleos de poboación, conleva tamén a un número maior de usuarios potenciais, o que pode dar orixe ó "efecto Mohring" (Mohring, 1972). Isto quere dicir que ante un incremento dos usuarios, a compañía de transportes responde cun aumento das frecuencias, o que permite ós usuarios reducir os seus tempos de espera (de Rus 2003). En canto ós servizos de conexións directas entre as cidades poderían ser denominadas como intercities.

Con respecto ás demais estacións en servizo na actualidade, cómpre destacar os casos de Osebe, Pontevedra-Universidade e Cesantes, con tan só un servizo diario por sentido. Cun número tan reducido de frecuencias diarias, é lóxico que presenten un número moi cativo de usuarios. Un caso moi semellante son as novas estacións situadas entre A Coruña e a capital galega, destacando o caso xa citado de Ordes-Fosado, con tan só 4 frecuencias por sentido.

Diferentes a estas dúas tipoloxías é o caso das localidades que na actualidade posúen dunha estación no propio centro urbano ou que teñen un número destacado de frecuencias. Neste 
conxunto están Padrón, Pontecesures, Arcade ou Redondela. Chama a atención que tratándose de estacións céntricas, vaian a ser clausuradas, mentres que hai unha aposta por estacións externas como vai ser o caso de Padrón-Barbanza. Esta última será un caso semellante ás actuais de de Cerceda-Meirama ou Ordes-Fosado.

\section{Conclusión}

A inminente finalización das obras no corredor ferroviario atlántico galego vai permitir unha grande mellora na mobilidade e na accesibilidade no eixo comprendido entre A Coruña e Vigo. Este corredor, vertebrado pola Autoestrada do Atlántico como principal arteria viaria, é fundamental non só en si mesmo (Ferrol-A Coruña-Santiago de Compostela-Vilagarcía de Arousa-Pontevedra-Vigo), senon tamén como auténtica espiña dorsal da mobilidade en toda a Galicia Occidental.

As importantes reducións nos tempos de desprazamento en ferrocarril van permitir un incremento da accesibilidade ferroviaria entre os nodos principais antes mencionados, agás Ferrol. Porén, a falla de mais servizos ferroviarios que alimenten este tronco principal será un lastre importante. Tampouco o transporte mediante autobús, en xeral, vai permitir unha intermodalidade cómoda e viable.

Por outra banda, o desmantelamento das vías do antigo ferrocarril convencional non permitirá a creación de servizos de cercanías a medio prazo. Galicia é unha das poucas comunidades que non conta con servizos ferroviarios de proximidade nas súas áreas metropolitanas, e isto é así non só pola deixadez de RENFE e ADIF, senon porque se poderían aproveitar mellor as potencialidades que outorga a autonomía galega, creando unha compañía galega de ferrocarrís, como existe noutras comunidades do Estado.

A posta en marcha deste servizo de alta velocidade (que de facto non sobrepasará os 200 $\mathrm{km} / \mathrm{h}$ ) traerá consigo unha perda de servizo en moitos núcleos intermedios onde o ferrocarril era unha referencia importante na mobilidade da poboación. Estacións tradicionais como Padrón serán substituidas por gares-verts como a denominada PadrónBarbanza, perdéndose así a centralidade que debe ter unha estación de ferrocarril. 
A aplicación do modelo de alta velocidade hexemónico en España á realidade galega plantexa moitos interrogantes. Entre eles encóntranse os grandes baleiros territoriais de servizo, a falta de conexión cos aeroportos e a escasa planificación da intermodalidade. Neste senso, é preciso salientar como punto feble os importantes retrasos que acumulan as obras de remodelación das estacións.

Por último, hai que lembrar que o proxecto non atende unha grande parte do Golfo Ártabro. Ferrol e comarca volven quedar descolgados do tren das infraestruturas, ao igual que o Baixo Miño. Do mesmo xeito, a nova infraestrutura non permitirá resolver a mellora da comunicación ferroviaria con Portugal, impedindo a creación de sinerxias na fachada occidental da Península Ibérica e freando o desenvolvemento da fachada oeste peninsular.

\section{Referencias bibliográficas}

BEIRAS TORRADO, X. M. (1972): O atraso económico de Galicia, Vigo: Ed. Galaxia.

COCA CASTAÑO, P. e COLOMER FERRÁNDIZ, J. V. (2010) (coords.): El transporte terrestre de mercancías. ValenciaPort. Valencia.

DE RUS, G.; CAMPOS, J. e NOMBELA, G. (2003). Economía del transporte. Antoni Bosch. Barcelona.

DOT (2011): Directrices de Ordenación do Territorio de Galicia. ed, Xunta de Galicia. Santiago de Compostela.

FERNÁNDEZ DÍAZ, X.C. (2009): El ferrocarril en Galicia 2. Ir Indo Edicións. Vigo.

FLORIDA, R., GULDEN, T. y MELLANDER, C. (2008): "The rise of the mega-region", Cambridge Journal of Regions, Economy and Society, 1(3), pp. 459-476.

LOIS GONZÁLEZ, R.C. e Piñeira Mantiñán, Mạ.J. (2011): "A rede urbana e a rápida urbanización do territorio", en Ma..J. Piñeira Mantiñán y Xosé M. Santos Solla (Coords.), Xeografía de Galicia. Pp. 157-227. Ed. Xerais. Vigo.

LOIS GONZÁLEZ, R.C. (2004): “Estructura territorial de Galicia”, en R. Rodríguez González (Dir.), Os concellos galegos para o século XXI. Análise dunha reestructuración do territorio e o goberno local. Vols. I e II. Pp. 100161. IDEGA-Universidade de Santiago. Santiago de Compostela.

LOIS GONZÁLEZ, R.C. e ALDREY VÁZQUEZ, J.A. (2010): “El problemático recorrido de la ordenación del territorio en Galicia", en Cuadernos Geográficos. El estado de la Ordenación del Territorio en España, núm. 47, 2010-2. Pp. 583-611. Universidad de Granada.

LOIS GONZÁLEZ, R.C. (2014): "As transformacións recentes nun rural galego que mudou", en P. Saavedra e R. Rodríguez González (Dir.), A Terra en Galicia. Pasado, presente e futuro. Pp. 112-138. Ed. Concello de Lalín, UIMP e Fundación Juana de Vega. Lalín.

LÓPEZ CARRO, M. R. (2014): Lectura xeográfica da cidade de Porto. Traballo Fin de Grao de Xeografía e Ordenación do Territorio. Facultade de Xeografía e Historia. Universidade de Santiago.

MOHRING, H. (1972): "Optimization and Scale Economies in Urban Bus Transportation". American Economic Review. Septiembre, pp. 591-604. 
NÁRDIZ ORTIZ, C. (2008): La gran calle de Galicia. Artículo de Opinión publicado en el diario La Voz de Galicia, día 13-12-2008. Disponible en la web: http://www.lavozdegalicia.es/opinion/2008/12/13/0003_7391491.htm

PAZOS OTÓN, M. (2005): Pontevedra litoral: hacia una ciudad continua. Ed. deputación Provincial de Pontevedra. Pontevedra.

PAZOS OTÓN, M. (2009): "Galicia: la governança de les infraestructures de transport: entre el model desarrollista i la mobilitat sostenible", en Idees: Revista de temes contemporanis, núm. 32. Pp. 218-240.

PÉREZ TOURIÑO, E. (dir.) (1997): Infraestructuras y desarrollo regional: efectos económicos de la Autopista del Atlántico. Editorial Civitas. Madrid.

PIÑEIRA MANTIÑÁN, Mạ.J. e SANTOS SOLLA, X.M. (Coords.) (2011): Xeografía de Galicia. Ed. Xerais. Vigo.

PRECEDO LEDO, A. (1987): Galicia: estructura del territorio y organización comarcal. Ed. Xunta de Galicia. Santiago de Compostela.

PIÑEIRA MANTIÑÁN, Mạ.J. e SANTOS SOLLA, X.M. (Coords.) (2011): Xeografía de Galicia. Ed, Xerais. Vigo.

RODRÍGUEZ BUGARÍN, M. e NÁRDIZ ORTIZ, C. (coords.) (1996): El ferrocarril en el Noroeste de España. Universidade da Coruña. A Coruña.

RODRÍGUEZ GONZÁLEZ, R. (2010): "A planificación territorial como proceso, o exemplo da planificación territorial desde o eixo atlántico", en Eixo Atlántico: revista da Eurorrexión Galicia-Norte de Portugal, núm 10 (Exemplar dedicado a: Eixo Atlántico: pasado, presente e futuro), págs. 35-43.

SOUTO GONZÁLEZ, X.M. (1988): Xeografía Humana. Biblioteca Básica da Cultura Galega. Ed. Galaxia. Vigo.

TROIN, J.-F. (1995): Rail et aménagement du territoire. Des héritages aux noveaux défis. Edisud. Aix-enProvence. 261 pp.

VVAA (2014): Cidades Subxacentes. Policentrismos urbanos en Galicia. Ed. Colectivo 1AUN.

VV.AA. (1984): Plan Director Territorial da Coordinación de Galicia. Xunta de Galicia e Ministerio de Obras Públicas e Urbanismo. Santiago de Compostela.

\section{Páxinas web consultadas}

http://www.camfergal.info O Camiño de Ferro en Galicia. El Ferrocarril en Galicia. Acceso: 14-1-2015 